\title{
Studies on the Ultraviolet Irradiation of Provitamin D and Its Related Compounds
}

\author{
II. Determination of Potential Vitamin $\mathrm{D}_{2}$ in Ultra- \\ violet Irradiated Products of Ergosterol by \\ Gas-Liquid Chromatography ${ }^{1}$
}

\author{
Tadashi Kobayashi and Mitsue Yasumura ${ }^{2}$ \\ Department of Hygienic Chemistry, Kobe Women's College \\ of Pharmacy, Higashinada-ku, Kobe (Post No. 658)
}

(Received February 7, 1972)

\begin{abstract}
Determination of potential vitamin $D_{2}$ (the sum of vitamin $D_{2}$ and pre- $D_{2}$ ) in UV irradiated products of ergosterol was investigated by a GLC method. Both vitamin $D_{2}$ and pre- $D_{2}$ were quantitatively isomerized into the thermal cyclized products "pyro- and isopyro- $D_{2}$ " by GLC. It was previously reported that the separation of pyro- $D_{2}$ from lumisterol ${ }_{2}$ was difficult $(6,7)$, but their separation has been found to be successfully achieved by applying the TMS ethers of samples to the GLC using the following apparatus and analytical conditions : apparatus, a Shimadzu GC-4APTF gas chromatograph equipped with a hydrogen flame ionization detector; column, a glass column $(0.4 \times 150 \mathrm{~cm})$ packed with $1.5 \%$ OV-17 on Shimalite W (80-100 mesh); column temperature, $215^{\circ}$; flow rate of nitrogen gas, $80 \mathrm{ml} / \mathrm{min}$. Recovery tests of vitamin $D_{2}$ in the mixtures of vitamin $D_{2}$ isomers by the GLC gave good results, and no special inhibitory peak was observed in the gas chromatogram of irradiated ergosterol products. From these results, the GLC procedure applicating the operating parameters mentioned above after trimethylsilylation of samples and using the peaks of pyro- $D_{2}$ TMS ether and stigmasteryl acetate as an internal standard was established as a routine method for the determination of potential vitamin $D_{2}$ in irradiated ergosterol products.

The effects of ergosterol concentrations, temperatures, solvents, use of a filter solution and light sources on the yield of potential vitamin $D_{2}$ were examined by using this method. The effects of light sources and ergosterol concentrations were large, whereas the other conditions gave little effects.
\end{abstract}

It has been well known that UV irradiation of ergosterol gives many isomers; vitamin $\mathrm{D}_{2}$, pre- $\mathrm{D}_{2}$, tachysterol $\mathrm{l}_{2}$, lumisterol 2 , toxisterols ${ }_{2} \mathrm{~A}$ and $\mathrm{B}$, suprasterols $\mathrm{I}$ and II and other unknown minor products. Pre- $\mathrm{D}_{2}$ is not photochemically but thermally isomerized into vitamin $\mathrm{D}_{2}$ and the reaction is accelerated at a temperature higher than $20^{\circ}$. Therefore, vitamin $\mathrm{D}_{2}$ and its

\footnotetext{
${ }^{1}$ Following abbreviations are used: UV, ultraviolet; pre- $\mathrm{D}_{2}$, previtamin $\mathrm{D}_{2}$ (preergocalciferol); pyro- $\mathrm{D}_{2}$, pyrovitamin $\mathrm{D}_{2}$ (pyroergocalciferol); isopyro- $\mathrm{D}_{2}$, isopyrovitamin $\mathrm{D}_{2}$ (isopyroergocalciferol); $\mathrm{S}$, stigmasteryl acetate; TLC, thin-layer chromatography; GLC, gas-liquid chromatography; TMS, trimethylsilyl.

2 小林 正, 康村満枝
} 


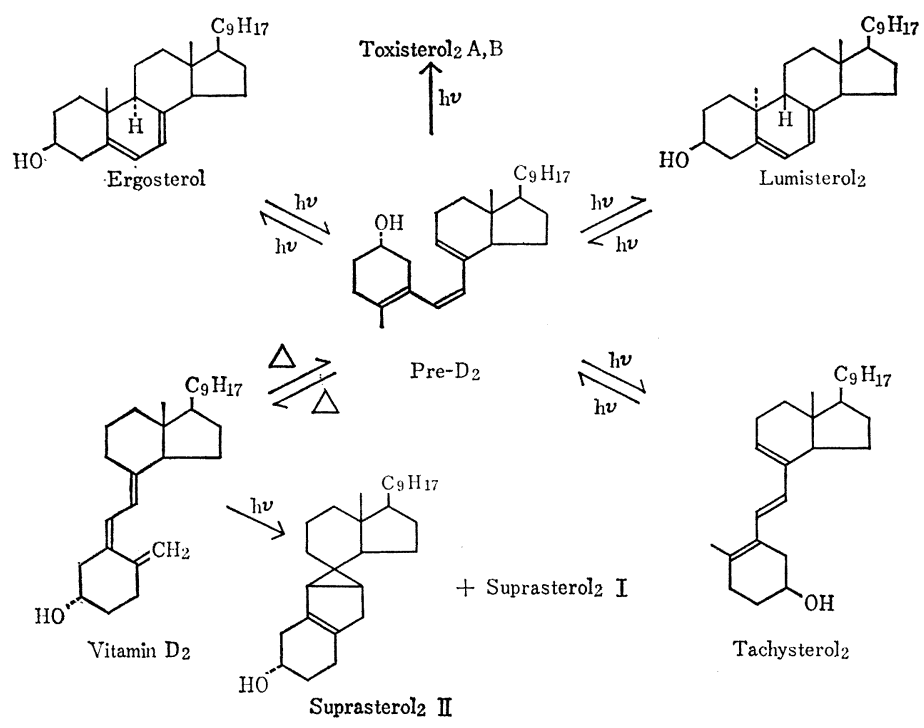

FIG. 1 Photoisomerization of ergosterol

photoisomers (suprasterols 2 I and II) are formed as detectable amounts by the irradiation at the mentioned temperature. The photoisomerization mechanism was confirmed as shown in Fig. 1 by Havinga and co-workers (1-3). The quantitative separation of these isomers is very important problems to develop the investigation on UV irradiation of ergosterol, but no satisfactory method has been appeared.

The readily isomerized thermal interconversion between pre- $\mathrm{D}_{2}$ and vitamin $\mathrm{D}_{2}$ gives a serious problem in vitamin $D_{2}$ assay. Since pre$\mathrm{D}_{2}$ has the possibility to convert into vitamin $\mathrm{D}_{2}$ during storage or in body at a temperature higher than $20^{\circ}$, pre- $\mathrm{D}_{2}$ can not be neglected in vitamin $\mathrm{D}_{2}$ assay although it has little biological potency. Hanewald et al. $(4,5)$ proposed that the distinction between the actual vitamin $\mathrm{D}_{2}$ (vitamin $\mathrm{D}_{2}$ alone) and the potential vitamin $\mathrm{D}_{2}$ (the sum of vitamin $\mathrm{D}_{2}$ and pre- $\mathrm{D}_{2}$ ) should be made and that the potential vitamin $D_{2}$ should be always estimated for the proper evaluation.

The quantitative TLC was previously reported to estimate the potential vitamin $D_{2}$ in UV irradiated ergosterol solution (6), but it was rather complicate to use as a routine method. One of the reasons was derived from the com- plicated procedure to estimate the sum of vitamin $D_{2}$ and pre- $D_{2}$ because the two compounds were separated to each other on TLC. In GLC analysis, however, both vitamin $\mathrm{D}_{2}$ and pre- $\mathrm{D}_{2}$ are thermally isomerized into the cyclized compounds "pyro- and isopyro- $\mathrm{D}_{2}$ " in the same manner at a temperature higher than $180^{\circ}$ and give the twin peaks derived from them on the gas chromatogram. The ratio between their peak areas is constant at a definite temperature. Therefore, a GLC method must be available for the determination of potential vitamin $D_{2}$ if the peak of either pyro- or isopyro- $D_{2}$ is quantitatively separated from the peaks of other isomers.

It was mentioned in the previous reports (6, 7) that the separations of pyro- $\mathrm{D}_{2}$ from lumisterol ${ }_{2}$ and of isopyro- $\mathrm{D}_{2}$ from large amounts of ergosterol were difficult in the GLC analysis of vitamin $\mathrm{D}_{2}$ isomers. Tsukida et al. (8) reported on the quantitative separation of vitamin $\mathrm{D}_{2}$ and $\mathrm{D}_{3}$ by the GLC using $1.5 \% \mathrm{OV}-17$ as a stationary phase. Recently, we found that a successful separation of pyro- $\mathrm{D}_{2}$ from lumisterol ${ }_{2}$ was achieved by applying the TMS ethers of vitamin $\mathrm{D}_{2}$ and lumisterol ${ }_{2}$ to the slightly modified GLC method from Tsukida et al. The quantitative separations of photoisomers of ergosterol and the simple routine method for 
the determination of potential vitamin $\mathrm{D}_{2}$ by the GLC are described in this paper.

\section{EXPERIMENTAL}

\section{Materials and Reagents}

Vitamin $D_{2}$ The commercial grade of Philips-Duphar Co. was recrystallized from acetonewater $(4: 1): \mathrm{mp} 115-116^{\circ}, \mathrm{E}_{1}^{1 \%} \mathrm{~cm}, 265 \mathrm{~m} \mu$ 461 (in ethanol).

Pre- $\mathrm{D}_{2} \quad$ Pre- $\mathrm{D}_{2}$ was obtained as a yellow oil by purifying the refluxed solution of vitamin $\mathrm{D}_{2}$ in ethylene dichloride on TLC: $\mathrm{E}_{1 \mathrm{~cm}, 263 \mathrm{~m} \mu}^{1 \%}$ 205 (in ethanol). It was kept at a temperature below $-10^{\circ}$.

Ergosterol The commercial grade of Sigma Chemical Co. was used.

Tachysterol $_{2}$ The unsaponifiable matters of tachysterol ${ }_{2}-4$-methyl-3,5-dinitrobenzoate kindly supplied by Philips-Duphar Co. were used.

Lumisterol $_{2}$ This was kindly supplied by Philips-Duphar Co.

Stigmasteryl Acetate Stigmasterol purchased from Nakarai Chem. Ind. Co. was acetylated according to the conventional method and recrystallized from acetone: $\mathrm{mp} 144^{\circ}$.

Internal Standard Solution Stigmasteryl acetate was dissolved in pyridine to make a concentration of $1 \mathrm{mg} / \mathrm{ml}$. This was used as the internal standard solution for GLC.

TMS Reagents Hexamethyldisilazane and trimethylchlorosilane were purchased from $\mathrm{Na}$ karai Chem. Ind. Co.

\section{Ultraviolet Irradiation of Ergosterol}

A weighed amount of ergosterol is dissolved in a suitable organic solvent to make a concentration of $0.5-2.0 \mathrm{mg} / \mathrm{ml}$. Three hundred to five hundred $\mathrm{ml}$ of this solution are put in the photochemical reaction apparatus of Taika Ind. Co. (internal irradiation type) and irradiated by either a high pressure $(100 \mathrm{~W})$ or a low pressure $(15 \mathrm{~W}) \mathrm{Hg}$ lamp with stirring by bubbles of nitrogen gas. The irradiation by a high pressure $\mathrm{Hg}$ lamp is usually carried out with use of 0.4 $\% \mathrm{NaNO}_{3}$ solution as a filter solution to absorb the rays below $250 \mathrm{~m} \mu$, whereas no filter solution is used in the case of low pressure $\mathrm{Hg}$ lamp.
3. Procedure for the Determination of Potential Vitamin $\mathrm{D}_{2}$

1) Preparation of Sample Solution

A ergosterol solution is irradiated according to the method mentioned above. A part of the solution equivalent to $2-4 \mathrm{mg}$ of ergosterol is accurately taken and evaporated to dryness under reduced pressure. The residue is dissolved in $2 \mathrm{ml}$ of pyridine. This solution is denoted as the sample solution.

2) Preparation of Vitamin $D_{2}$ Standard Solution

Vitamin $\mathrm{D}_{2}$ is dissolved in pyridine to make a concentration of $1 \mathrm{mg} / \mathrm{ml}$. This solution is denoted as the vitamin $\mathrm{D}_{2}$ standard solution.

3) Trimethylsilylation

After mixing $1 \mathrm{ml}$ of either the sample or vitamin $\mathrm{D}_{2}$ standard solution with $1 \mathrm{ml}$ of the internal standard solution, trimethylsilylation is carried out by mixing with $0.5 \mathrm{ml}$ of hexamethyldisilazane and $0.1 \mathrm{ml}$ of trimethylchlorosilane and then allowing to stand for $10 \mathrm{~min}$ at a room temperature. The precipitation formed by addition of TMS reagents is eliminated by centrifugation for $15 \mathrm{~min}$. These supernatants are denoted as the GLC sample and GLC vitamin $\mathrm{D}_{2}$ standard solutions.

4) GLC Analysis

Five $\mu \mathrm{l}$ of either the GLC sample or GLC vitamin $\mathrm{D}_{2}$ standard solution taken by a $10 \mu \mathrm{l}$ microsyringe are applied to the GLC using the following apparatus and analytical conditions:

Apparatus A Shimadzu GC-4APTF gas chromatograph equipped with a hydrogen flame ionization detector.

Column A glass column $(0.4 \times 150 \mathrm{~cm})$ packed with $1.5 \%$ OV -17 on $80-100$ mesh of Shimalite W (purchased from Shimadzu Co.).

Operating Parameters Temperatures: column $215^{\circ}$, detector $300^{\circ}$, injection port $280^{\circ}$; Flow rate of carrier gas $\left(\mathrm{N}_{2}\right), 80 \mathrm{ml} / \mathrm{min}$.

\section{5) Calculation}

The peak area ratios of pyro- $\mathrm{D}_{2}$ TMS ether to stigmasteryl acetate are estimated on the GLC sample and GLC vitamin $\mathrm{D}_{2}$ standard solutions, respectively. The content of potential vitamin $\mathrm{D}_{2}$ in irradiated ergosterol solution $(\mathrm{mg}$ $/ \mathrm{ml}$ ) is calculated by the following formula: 
Content of Potential Vitamin $\mathrm{D}_{2}(\mathrm{mg} / \mathrm{ml})$

$=\mathrm{P}_{\mathrm{sa}} / \mathrm{P}_{\mathrm{st}} \times 2 / \mathrm{V} \times 1.0$

$\mathrm{P}_{\mathrm{sa}}$ : Peak area ratio on the GLC sample solution

$\mathrm{P}_{\mathrm{st}}$ : Peak area ratio on the GLC vitamin $\mathrm{D}_{2}$ standard solution

$\mathrm{V}$ : Volume taken from the irradiated ergosterol solution to make the sample solution

1.0 : Concentration of vitamin $\mathrm{D}_{2}(\mathrm{mg} / \mathrm{ml})$ in the vitamin $\mathrm{D}_{2}$ standard solution

\section{Results}

\section{Gas Chromatograms of Vitamin $D_{2}$} and Previtamin $\mathrm{D}_{2}$

When vitamin $\mathrm{D}_{2}$ was applied to the GLC described in the procedure 3) and 4), the twin peaks due to pyro- and isopyro- $\mathrm{D}_{2}$ TMS ethers were observed in the gas chromatogram as shown in Fig. 2. An unknown miner peak was accompanied with the peak of pyro- $\mathrm{D}_{2}$ TMS ether, but it did not disturb the estimation of the pyro peak.

Since pre- $\mathrm{D}_{2}$ is also thermally isomerized into pyro- and isopyro- $\mathrm{D}_{2}$, the gas chromatogram of its TMS ether was same as that of vitamin $\mathrm{D}_{2}$ TMS ether.

\section{Calibration Curves}

Four tenth to two $\mathrm{mg} / \mathrm{ml}$ of vitamin $\mathrm{D}_{2}$ pyridine solutions were applied to the GLC described in the procedure 3) and 4) in order to obtain the calibration curves. Linear correlations between the weight ratios (vitamin $\mathrm{D}_{2} /$ $\mathrm{S}$ ) and the peak ratios (pyro- or isopyro- $\mathrm{D}_{2}$ TMS ether/S) were obtained as shown in Fig. 3. These results showed that the yield of pyro-

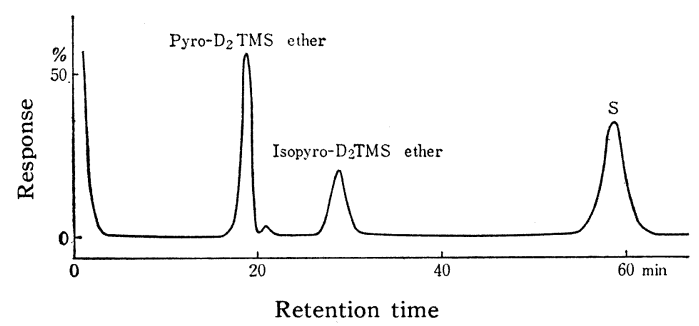

FIG. 2 Gas chromatogram of mixture of vitamin $D_{2}$ TMS ether and stigmasteryl acetate $(S)$

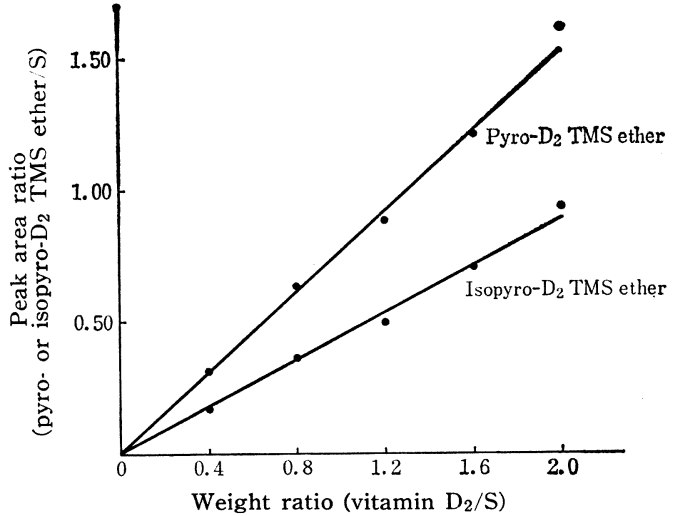

FIG. 3 Calibration curves of vitamin $D_{2}$ TMS ether by the gas-liquid chromatography

and isopyro- $\mathrm{D}_{2}$ TMS ethers was constant at a definite temperature and that the both peaks were available for the determination of potential vitamin $\mathrm{D}_{2}$.

3. Gas Chromatograms of Vitamin $\mathrm{D}_{2}$ Isomers in Mixtures and Irradiated Ergosterol Products

One mg of vitamin $\mathrm{D}_{2}, 0.5 \mathrm{mg}$ of lumisterol ${ }_{2}$, $1 \mathrm{mg}$ of ergosterol and $1 \mathrm{mg}$ of tachysterol ${ }_{2}$ in mixtures were dissolved in $1 \mathrm{ml}$ of pyridine and then added to $1 \mathrm{ml}$ of the internal standard solution. The mixed solution was applied to the GLC described in the procedure 4) with or without trimethylsilylation. The gas chromatograms are shown in Fig. 4 (A) and (B). The separation of pyro- $\mathrm{D}_{2}$ from lumisterol ${ }_{2}$ was impossible in the mixtures without trimethylsilylation, whereas their separation was successfully achieved after trimethylsilylation. The peaks of isopyro- $\mathrm{D}_{2}$ and its TMS ether were separated from those of other isomers, but the availability of these peaks was little as mentioned in the discussion part. Therefore, trimethylsilylation must be essential for the determination.

Secondarily, an ethanol solution of ergosterol was irradiated for $45 \mathrm{~min}$ by a high pressure $\mathrm{Hg}$ lamp and then treated according to the procedure. As shown in Fig. 4 (C), the gas chromatogram was similar to that of the TMS ethers of vitamin $D_{2}$ isomers in mixtures and no special inhibitory peak was observed in it. 

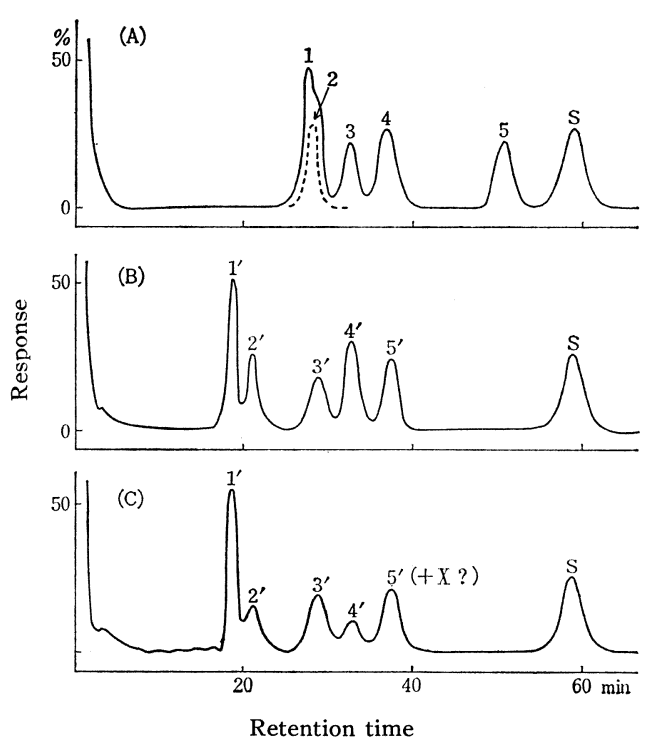

FIG. 4 Gas chromatograms of vitamin $D_{2}$ isomers in mixtures and irradiated ergosterol products

(A) Vitamin $\mathrm{D}_{2}$ isomers and $\mathrm{S}$ without trimethylsilylation; (B) Vitamin $\mathrm{D}_{2}$ isomers and $\mathrm{S}$ with trimethylsilylation; (C) Irradiated ergosterol products and $\mathrm{S}$ with trimethylsilylation.

1 and $1^{\prime}$, pyro- $\mathrm{D}_{2}$ and its TMS ether; 2 and $2^{\prime}$, lumisterol $l_{2}$ and its TMS ether; 3 and $3^{\prime}$, isopyro- $\mathrm{D}_{2}$ and its TMS ether; 4 and $4^{\prime}$, ergosterol and its TMS ether; 5 and $5^{\prime}$, tachysterol ${ }_{2}$ and its TMS ether; X, X substance

4. Recoveries of Vitamin $D_{2}$ in the Mixtures of Vitamin $D_{2}$, Lumisterol L Ergosterol $_{2}$ and Tachysterol ${ }_{2}$

One $\mathrm{mg}$ of vitamin $\mathrm{D}_{2}, 0.5 \mathrm{mg}$ of lumiste$\mathrm{rol}_{2}, 1 \mathrm{mg}$ of ergosterol and $1 \mathrm{mg}$ of tachysterol ${ }_{2}$ in mixtures were dissolved in $1 \mathrm{ml}$ of pyridine and then treated according to the procedure 2)$5)$ to obtain the recoveries of vitamin $\mathrm{D}_{2}$. As shown in Table 1 , the average recovery and standard deviation were $101.3 \pm 1.6 \%$. These results induced the conclusion that this method was available for the determination.

5. Determination of Potential Vitamin $\mathrm{D}_{2}$ in the Irradiated Ergosterol Solutions in Various Concentrations

One half, 1.0 and $2.0 \mathrm{mg} / \mathrm{ml}$ of ethanol solutions of ergosterol were irradiated by a high pressure $\mathrm{Hg}$ lamp with use of a filter solution. The temperatures were kept below $20^{\circ}$ during
TABLE 1

Recoveries of vitamin $D_{2}$ in the mixtures of vitamin $D_{2}$, lumisterol $l_{2}$ ergosterol and tachy. sterol ${ }_{2}$ by the gas chromatography

\begin{tabular}{cccc}
\hline & \multicolumn{2}{c}{$\begin{array}{c}\text { Ratio of peak areas } \\
\text { (pyro- } \text { D }_{2} \text { TMS/S) }\end{array}$} & Recovery \\
\cline { 2 - 3 } & Sample & Standard & \\
\hline & & & per cent \\
1 & 0.8177 & 0.7826 & 104.0 \\
2 & 0.8030 & 0.7826 & 102.1 \\
3 & 0.7780 & 0.7826 & 99.0 \\
4 & 0.8009 & 0.7826 & 101.9 \\
5 & 0.7832 & 0.7826 & 99.6 \\
\hline & & $\mathrm{M} \pm \mathrm{SD}$ & $101.3 \pm 1.6$ \\
\hline
\end{tabular}

TABLE 2

Determination of potential vitamin $\mathrm{D}_{2}$ in irradiated ergosterol solutions in ethanol

\begin{tabular}{cccc}
\hline \multirow{2}{*}{$\begin{array}{c}\text { Irradiation } \\
\text { time }\end{array}$} & \multicolumn{3}{c}{ Yield of potential vitamin $D_{2}$} \\
\cline { 2 - 4 } & Erg $0.5 \mathrm{mg} / \mathrm{ml}$ & Erg $1.0 \mathrm{mg} / \mathrm{ml}$ & Erg $2.0 \mathrm{mg} / \mathrm{ml}$ \\
\hline min & \multicolumn{4}{|}{ per cent } \\
10 & 28.3 & - & - \\
20 & 27.9 & 29.4 & - \\
30 & 26.4 & 31.8 & 32.7 \\
45 & 25.1 & 33.7 & - \\
60 & - & 29.7 & 34.4 \\
90 & - & 28.6 & - \\
120 & - & - & 33.3 \\
180 & - & - & 29.4 \\
240 & - & - & 27.1 \\
\end{tabular}

Light source: High pressure Hg lamp

Filter solution : $0.4 \% \mathrm{NaNO}_{3}$ solution

Irradiated temperature : below $20^{\circ}$

Erg: Ergosterol

irradiations. The contents of potential vitamin $\mathrm{D}_{2}$ in them were determined by applying to the whole procedure according to lapse of time. The yield of potential vitamin $\mathrm{D}_{2}$ for the initial contents of ergosterol is shown in Table. 2 The maximum yields of the three solutions were observed as 28.3, 33.7 and $34.4 \%$ at 10,45 and $60 \mathrm{~min}$ irradiations, respectively. Longer time irradiations after reaching maxima gave the effect to decrease the yield slowly.

6. Yield of Potential Vitamin $D_{2}$ in the Irradiated Ergosterol Solutions under Various Conditions

One $\mathrm{mg} / \mathrm{ml}$ of ergosterol solutions was irradiated under the various conditions described in Table 3 to confirm the effect of temperatures, filter solution, solvents and light sources on the 
TABLE 3

Determination of potential vitamin $\mathrm{D}_{2}$ in the ergosterol solutions irradiated under various conditions

\begin{tabular}{|c|c|c|c|c|}
\hline Solvent & $\begin{array}{l}\text { Light } \\
\text { source }\end{array}$ & $\begin{array}{c}\text { Filter } \\
\text { solution }\end{array}$ & Temperature & $\begin{array}{l}\text { Yield of } \\
\text { potential } \\
\text { vitamin D }\end{array}$ \\
\hline & & & & per cent \\
\hline $\begin{array}{l}\text { Ethanol } \\
\text { \# }\end{array}$ & $\begin{array}{l}\mathrm{Hv} \\
\#\end{array}$ & $0.4 \% \mathrm{NaNO}_{3}$ & $\begin{array}{c}\text { below } 20^{\circ} \\
\text { ” }\end{array}$ & $\begin{array}{l}31.8 \\
30.2\end{array}$ \\
\hline$"$ & $"$ & $0.4 \% \mathrm{NaNO}_{3}$ & $64-66^{\circ}$ & 33.7 \\
\hline n-Heptane & $"$ & " & below $20^{\circ}$ & 28.7 \\
\hline n-Hexane & $"$ & $"$ & $"$ & 35.3 \\
\hline Cyclohexane & e $"$ & $"$ & $"$ & 32.1 \\
\hline Ether & $"$ & " & " & 35.5 \\
\hline Ethanol & Lv & - & ", r r r & 19.8 \\
\hline$"$ & $"$ & - & $78^{\circ}$ & 17.6 \\
\hline
\end{tabular}

Concentration of ergosterol solution : $1.0 \mathrm{mg} / \mathrm{ml}$, Irradiation time: $30 \mathrm{~min}, \mathrm{Hv}$ : High pressure $\mathrm{Hg}$ lamp, Lv: Low pressure $\mathrm{Hg}$ lamp

yield of potential vitamin $\mathrm{D}_{2}$. The results are shown in Table 3 . The yields obtained by the irradiations with a high pressure $\mathrm{Hg}$ lamp were between 30 and $35.5 \%$ except the case of $n$ heptane solution $(28.7 \%)$. Therefore, temperatures, solvents and use of filter solution at the irradiations might give little effects on the yield of potential vitamin $\mathrm{D}_{2}$. On the other hand, the yields obtained by the irradiations with a low pressure $\mathrm{Hg}$ lamp were 19.8 and $17.6 \%$ which were significantly lower than the results of a high pressure $\mathrm{Hg}$ lamp.

\section{Discussion}

After investigating on column sizes, stationary phases, operating column temperatures and flow rates of carrier gas, the best conditions for the GLC were confirmed as described in the procedure 4). Both vitamin $\mathrm{D}_{2}$ and pre- $\mathrm{D}_{2}$ were thermally isomerized into pyro- and isopyro- $\mathrm{D}_{2}$ by the GLC, but their yielding rates were quantitative at a definite temperature as shown in Fig. 3.

When vitamin $D_{2}$ isomers in mixtures were applied to the GLC without trimethylsilylation, the separation of pyro- $\mathrm{D}_{2}$ from lumisterol ${ }_{2}$ could not be achieved. However, the application of trimethylsilylation brought their successful separation as shown in Fig. 4. On the other hand, isopyro- $\mathrm{D}_{2}$ could not be separated from large amounts of ergosterol even though trimethylsilylation was applied. Since large amounts of ergosterol as the original compound may be remained in sample solutions if irradiation times are short, the availability of isopyro- $\mathrm{D}_{2}$ must be little for the purpose. From these results, the application of trimethylsilylation and the use of pyro- $\mathrm{D}_{2}$ TMS peak were successfully presented for the routine method including these procedures.

The yields of potential vitamin $\mathrm{D}_{2}$ in the ergosterol solutions irradiated under various conditions were estimated by using this method. When concentrations of ergosterol solutions were higher, longer irradiations were necessary to get the maximum yield of potential vitamin $D_{2}$, as shown in Table 2. However, further irradiations after reaching the maxima gave the effects to decrease the yield. The effects of temperatures, solvents and use of a filter solution at the irradiations were little on the yield, whereas the effects of light sources were large as shown in Table 3. These results showed that wave lengths with light intensities might be very important at the irradiations.

\section{ACKNOWLEDGements}

The authors wish to thank Dr. K. Tsukida and Miss K. Saiki of the College for their helpful discussions and also wish to thank Philips-Duphar Co. for gifts of lumisterol ${ }_{2}$ and tachysterol ${ }_{2}-4-$ methyl-3, $_{5}$ 5-dinitrobenzoate.

\section{REFERENCES}

1. Rappoldt, M.P., and Havinga, E., Rec. trav. Chim., 79, 369 (1960).

2. Rappoldt, M.P., Rec. trav. Chim., 79, 392, 1012 (1960).

3. Sanders, G. M., and Havinga, E., Rec. trav. Chim., 83, 665 (1964).

4. Hanewald, K.H., Mulder, F. J., and Keuning, K. J., J. Pharm. Sci., 57, 1308 (1968).

5. Keverling Buisman, J. A., Hanewald, K. H., Mulder, F. J., Roborgh, J. R., and Keuning, K. J., J. Pharm. Sci., 57, 1326 (1968).

6. Kobayashi, T., and Yasumura, M., Vitamins, 44, 133 (1971).

7. Kobayashi, T., J. Vitaminol., 13, 255 (1967).

8. Tsukida, K., and Saiki, K., J. Vitaminol., 16, 293 (1970). 